\title{
ERRATUM
}

\section{Erratum to: Response to Deep Brain Stimulation in the Lateral Hypothalamic Area in a Rat Model of Obesity: In Vivo Assessment of Brain Glucose Metabolism}

María Luisa Soto-Montenegro, ${ }^{1,2}$ Javier Pascau, ${ }^{2,3}$ Manuel Desco ${ }^{1,2,3}$

${ }^{1}$ Unidad de Medicina y Cirugía Experimental, Instituto de Investigación Sanitaria Gregorio Marañón, Dr. Esquerdo, 46, Madrid, Spain

${ }^{2}$ CIBER de Salud Mental (CIBERSAM), Madrid, Spain

${ }^{3}$ Departamento de Bioingeniería e Ingeniería Aeroespacial, Universidad Carlos III de Madrid, Madrid, Spain

Erratum to: Mol Imaging Biol (2014) 16: 830-837

DOI: 10.1007/s11307-014-0753-0

In the methods, a sentence that stated: "DBS was conducted in a constant current mode at $130 \mathrm{~Hz}$ and $300 \mu \mathrm{A}$ with a pulse width of $60 \mu \mathrm{s}$." was in error.

The methods should be: "DBS was conducted in a constant current mode at $130 \mathrm{~Hz}$ and $150 \mu \mathrm{A}$ with a pulse width of $100 \mu$ s."

The online version of the original article can be found at http://dx.doi.org/ 10.1007/s11307-014-0753-0. 